\title{
Tight Interplay between Replication Stress and Competence Induction in Streptococcus pneumoniae
}

\author{
Vanessa Khemici ${ }^{1,2,+}$, Marc Prudhomme ${ }^{1,2,+}$ and Patrice Polard ${ }^{1,2, *}$ \\ 1 Laboratoire de Microbiologie et Génétique Moléculaires (LMGM), Centre de Biologie Integrative (CBI), \\ Centre National de la Recherche Scientifique (CNRS), 31062 Toulouse, France; vkemici@gmail.com (V.K.); \\ marc.prudhomme@univ-tlse3.fr (M.P.) \\ 2 Université de Toulouse, Université Paul Sabatier, 31062 Toulouse, France \\ * Correspondence: patrice.polard@univ-tlse3.fr \\ + These authors equally contributed to this work.
}

check for updates

Citation: Khemici, V.; Prudhomme, M.; Polard, P. Tight Interplay between Replication Stress and Competence Induction in Streptococcus pneumoniae. Cells 2021, 10, 1938. https://doi.org/ 10.3390/cells10081938

Academic Editors: Bernard S. Lopez and Ivan Matic

Received: 28 May 2021

Accepted: 20 July 2021

Published: 30 July 2021

Publisher's Note: MDPI stays neutral with regard to jurisdictional claims in published maps and institutional affiliations.

Copyright: (c) 2021 by the authors. Licensee MDPI, Basel, Switzerland. This article is an open access article distributed under the terms and conditions of the Creative Commons Attribution (CC BY) license (https:/ / creativecommons.org/licenses/by/ $4.0 /)$.

\begin{abstract}
Cells respond to genome damage by inducing restorative programs, typified by the SOS response of Escherichia coli. Streptococcus pneumoniae (the pneumococcus), with no equivalent to the SOS system, induces the genetic program of competence in response to many types of stress, including genotoxic drugs. The pneumococcal competence regulon is controlled by the originproximal, auto-inducible com $\mathrm{CDE}$ operon. It was previously proposed that replication stress induces competence through continued initiation of replication in cells with arrested forks, thereby increasing the relative com $\mathrm{CDE}$ gene dosage and expression and accelerating the onset of competence. We have further investigated competence induction by genome stress. We find that absence of RecA recombinase stimulates competence induction, in contrast to SOS response, and that double-strand break repair $(\operatorname{RexB})$ and gap repair $(\mathrm{RecO}, \mathrm{RecR})$ initiation effectors confer a similar effect, implying that recombinational repair removes competence induction signals. Failure of replication forks provoked by titrating PolC polymerase with the base analogue HPUra, over-supplying DnaA initiator, or under-supplying DnaE polymerase or DnaC helicase stimulated competence induction. This induction was not correlated with concurrent changes in origin-proximal gene dosage. Our results point to arrested and unrepaired replication forks, rather than increased com CDE dosage, as a basic trigger of pneumococcal competence.
\end{abstract}

Keywords: DNA damage response; genome integrity; replication stress; recombinational repair; bacterial competence; Streptococcus pneumoniae

\section{Introduction}

All genomes are susceptible to potentially life-threatening damage, of both environmental and endogenous origin. To confront this challenge to their survival, organisms have evolved a range of repair pathways, notably those inducible by the damage itself. The first program found to be triggered in response to DNA damage was the SOS response of Escherichia coli $[1,2]$. It is set in motion when some mishap generates single-stranded DNA on which the RecA protein polymerizes; the resulting nucleofilament activates autoproteolysis of the transcriptional repressor LexA and thus expression of the LexA-controlled genes that provide DNA repair functions.

The SOS system is widespread in bacteria but not universal, and some species have evolved other responses to genome damage [3]. A prominent example is Streptococcus pneumoniae (the pneumococcus), which does not encode a LexA homologue but responds to genotoxic agents by developing the distinct physiological state of competence [4]. Competence provides the cells with new properties, including the well-known horizontal gene transfer process of genetic transformation [5]. Many species share this ability to convert to competence for transformation, as well as a similarity of mechanism in the importing of external DNA across the cell membrane and integration into the genome by RecA-directed 
homologous recombination [5]. On the other hand, regulation of competence appears specific to each species, reflecting the distinct integration of the genetic program into each bacterial lifestyle [6]. Here, we report our analysis of pneumococcal competence induction in response to various types of genome stress that disrupt DNA recombination and replication dynamics.

The core of pneumococcal competence control is a two-component system (TCS) consisting of the histidine kinase ComD and the transcription regulator ComE [6,7]. The ComDE TCS is modulated by a competence-stimulating peptide (CSP), encoded by the $\operatorname{comC}$ gene in the form of a pre-CSP that is matured and exported through the cell membrane by the $\mathrm{ABC}$ transporter Com $\mathrm{AB}$. These elements define a positive feedback loop, termed the ComABCDE core sensing system, which integrates various kinds of stress and coordinates development of competence in the population (Figure 1A; [8]). In liquid cultures, competence induction occurs only during the exponential phase of growth and after a time delay characteristic of the strain and growth conditions (a 'pre-competence' period referred to as $X_{A}$; Figure 1A [9]). Induction of competence results in two successive transcriptional waves, termed early and late. The early wave is initiated by ComE upon its phosphorylation by ComD [8,10]. Phosphorylated ComE activates about 20 early competence (com) genes, including $\operatorname{com} \mathrm{X}$ whose product, the sigma factor $\sigma^{\mathrm{X}}$, primes the late wave by governing the transcription of about 60 other com genes. The $\sigma^{\mathrm{X}}$ regulon includes DprA that, in addition to mediating RecA-directed recombination during transformation [11], interacts with phosphorylated ComE to shut off competence [12]. Thus, the shift to competence as measured by com gene expression is transient, lasting for roughly one generation (referred to as the $X_{\mathrm{B}}$ period [9]; Figure 1A). A feature of pneumococcal competence is that it develops only during the exponential phase of growth, during which the replicative state of the chromosome renders it particularly sensitive to damage or disruption.

A

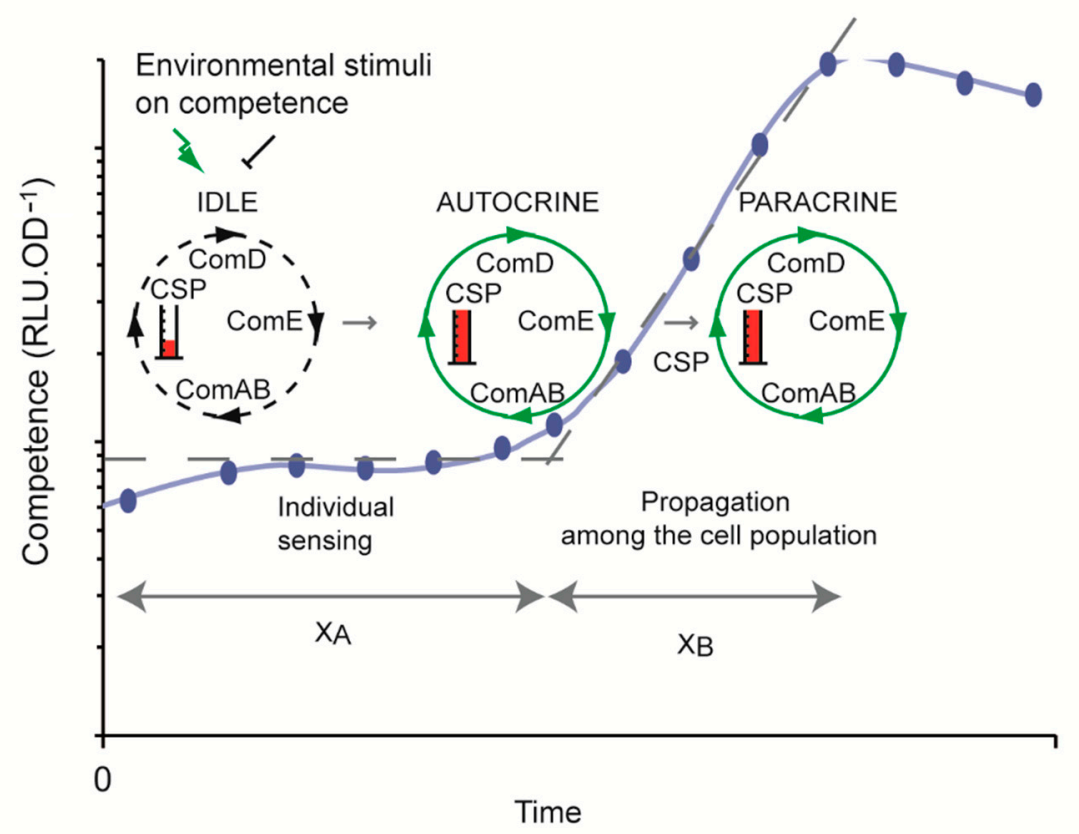

Figure 1. Cont. 
B

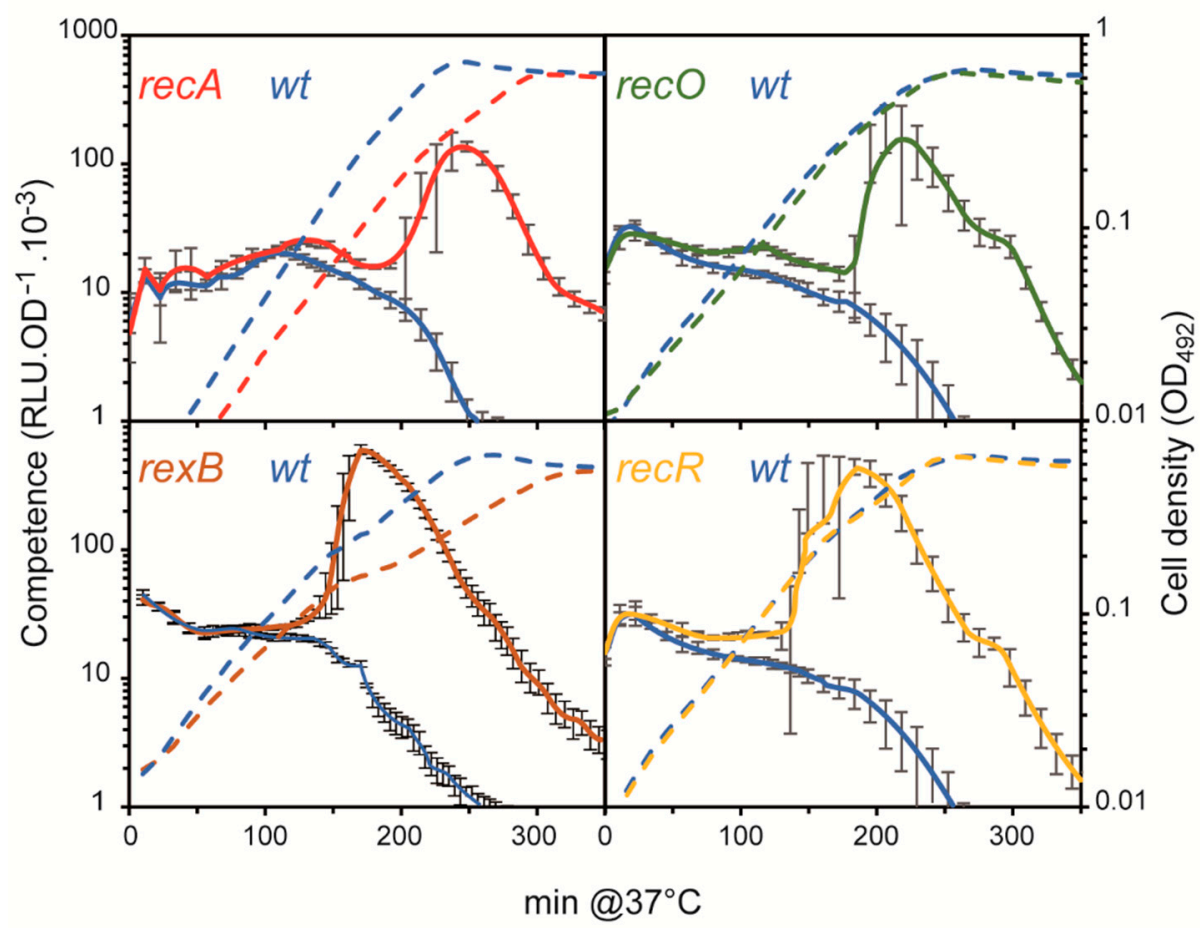

Figure 1. Pneumococcal competence development cycle: effect of repair-deficiency mutations. (A): Model of competence development in S. pneumoniae. The blue dots/blue line shows the development of competence in an exponentially growing culture measured by a transcriptional fusion of the luciferase gene in specific activity (Relative luminescence units (RLU) divided by the cell density (OD)); the growth curve is omitted for clarity. The core sensing and regulatory machinery of competence are composed of the $\operatorname{com} A, \operatorname{com} B, \operatorname{com} C$ (CSP), comD, and $\operatorname{com} E$ gene products, which define a positive feedback loop referred to as ComABCDE. The green arrow and the black T-bar represent external positive and negative inputs, which balance the idling of the core sensing machinery. At some point, growth conditions will provide enough positive input to activate the ComABCDE positive feedback loop in an autocrine mode in some of the cells. Next, this fraction of cells propagates competence within the population in a paracrine mode by transmitting the CSP via cell-to-cell contact. In this model, the autocrine and paracrine modes of competence development proceed in two distinct periods defined as $X_{A}$ and $X_{B}$, respectively [9]. $X_{B}$ is followed by shut-off of competence gene expression. The dashed grey lines represent competence gene expression during the $X_{A}$ and $X_{B}$ periods. (B): RecA recombination repair pathways prevent competence development. Cells were grown in $\mathrm{C}+\mathrm{Y}$ medium with initial $\mathrm{pH}$ adjusted with $\mathrm{HCl}$ to inhibit competence development of the reference strains R825 or R895 (blue curves); see also Figure S1. Competence of the population is shown as solid lines $\left(\right.$ RLU.OD $\left.{ }_{492}{ }^{-1} \times 10^{3}\right)$ and cell density as dashed lines $\left(\mathrm{OD}_{492}\right)$. Each panel shows a comparison of competence development of the WT strain with that of the mutant strains $\operatorname{rec}^{-}$(R3309; red), rex $\mathrm{B}^{-}$(R4036; light brown), recO $\mathrm{O}^{-}$(R2411; dark green), and $r e c \mathrm{R}^{-}$(R2412; orange) with that of their respective isogenic WT (wild type) strain ( $\mathrm{R} 825$ for $r e c \mathrm{~A}^{-}$and $r e x \mathrm{~B}^{-}$strains, and R895 for the others). Data are the means of at least five independent experiments, with standard deviations shown for the RLU.OD ${ }_{492}{ }^{-1}$ measurements.

A previous study showed pneumococcal competence to be induced by drugs that alter genome integrity or replication [13]. Competence was proposed to substitute for the SOS system in the pneumococcus, which does not possess a LexA homologue [4,14]. This raised the question of how replication stress signals are conveyed to the ComDE-mediated competence induction system. It was observed that these stresses were correlated with increased abundance of transcripts originating from the ori-proximal comCDE operon whose gene dosage had risen as a result of deceleration of the replication forks [15]. Here, 
we have further studied the signaling that triggers competence development following genome damage in the pneumococcus. We first found that $\operatorname{Rec} A$ and the main homologous recombination pathways RexAB and RecFOR are not involved in this signaling. Rather, RecA prevents competence development via its recombinational repair activity. While we also observed a link between fork arrest and competence development, our results do not support the notion that signaling stems from a com CDE gene dosage effect. Instead, they suggest that arrested and unrepaired replication forks are the trigger for competence induction.

\section{Material and Methods}

2.1. Pneumococcal Strains, Cell Growth, Competence Recording, and Transformation Procedures

Streptococcus pneumoniae strains used in this study are listed in Table S1. They are all derivatives of R800, which derives from the unencapsulated R6 strain originating from D39 lineage [9].

All strains were stored at $-70^{\circ} \mathrm{C}$ in the form of stock cultures, which were used to inoculate liquid fresh medium to measure competence development under the distinct conditions described in the text and/or the figures legends. Stock cultures were prepared at $37{ }^{\circ} \mathrm{C}$ in liquid $\mathrm{C}+\mathrm{Y}$ medium [16] at $\mathrm{pH} 6.8$ to impede spontaneous competence development. Cells were grown to $\mathrm{OD}_{550}=0.2$, centrifuged at $6000 \mathrm{rpm}$ for $5 \mathrm{~min}$ at $4{ }^{\circ} \mathrm{C}$ to discard the medium, resuspended with fresh $\mathrm{C}+\mathrm{Y}$ medium containing $15 \%$ glycerol to $\mathrm{OD}_{550}=0.4$, and kept frozen at $-70{ }^{\circ} \mathrm{C}$. In the case of ${ }^{\mathrm{e}} \mathrm{P}_{l a c}:: d n a A,{ }^{\mathrm{e}} \mathrm{P}_{l a c}:: d n a E$, and ${ }^{\mathrm{e}} \mathrm{P}_{l a c}:: d n a C$ strains, $\mathrm{C}+\mathrm{Y}$ medium was supplemented with $10 \mu \mathrm{M}$ IPTG, which is the concentration that results in a WT growth rate and ori/ter ratio value.

Competence was monitored in real time over the growth of the cell population by using a transcriptional fusion between the $l u c$ firefly luciferase gene and the $\operatorname{com} \mathrm{C}$ promoter (in the case of the $r e c \mathrm{~A}^{-}$and $r e x \mathrm{~B}^{-}$strains, along with the isogenic WT (wild type) strain) or $s s b \mathrm{~B}$ promoter (in all other mutant strains, along with the isogenic WT strain), as listed in Table S1. Cultures were started by diluting the stock cultures 50 - or 100 -fold in $\mathrm{C}+\mathrm{Y}$ medium adjusted to the desired $\mathrm{pH}$ and supplemented with luciferin in a 96-well white NBS micro plate (Corning) [17]. Relative luminescence units (RLU) and $\mathrm{OD}_{492}$ values were recorded every 5 to $10 \mathrm{~min}$ (depending on the experiment) during growth at $37^{\circ} \mathrm{C}$ with no shaking in a Varioskan Flash luminometer (Thermo Fisher Scientific Waltham, MA, USA).

HPUra (6( $p$-Hydroxyphenylazo)-uracil), MMC (mitomycin-C) and IPTG were added to the growth medium at the final concentrations indicated in the figures. $\mathrm{OD}_{492}$ values and luminescence values reported as $\mathrm{RLU} / \mathrm{OD}_{492}$ ratio were measured in real time over the growth of each strain under the different conditions described in the figures. Each figure reports a representative experiment or a mean (and standard deviation) of at least three independent experiments, which gave rise to similar results.

For the plating tests, stock cultures were 10-fold serially diluted, spotted on CATagar [18] containing $2 \%$ horse blood, 500 units/mL of catalase and IPTG (as indicated), and incubated overnight at $37^{\circ} \mathrm{C}$.

Genome modifications were performed by natural transformation with the use of chromosomal or PCR fragments as transforming DNA (tDNA), following the procedure described previously [19]. Briefly, freshly inoculated stock cells were treated at $37^{\circ} \mathrm{C}$ for $10 \mathrm{~min}$ with synthetic Competence-Stimulating Peptide (CSP1; $100 \mathrm{ng} \mathrm{mL}{ }^{-1}$ ) to induce competence for genetic transformation. Next, tDNA was added to the competent cells, which were further incubated for $20 \mathrm{~min}$ at $30{ }^{\circ} \mathrm{C}$ before plating on CAT-agar plates supplemented with $4 \%$ horse blood and, when required, with the appropriate concentration of the following antibiotics and after phenotypic expression for $120 \mathrm{~min}$ at $37^{\circ} \mathrm{C}$ : kanamycin $(\mathrm{Kn}$; $\left.500 \mu \mathrm{g} \mathrm{mL}^{-1}\right)$, spectinomycin (Spc; $\left.200 \mu \mathrm{g} \mathrm{mL}{ }^{-1}\right)$, and chloramphenicol $\left(\mathrm{Cm} ; 9 \mu \mathrm{g} \mathrm{mL}{ }^{-1}\right)$. Constructs obtained with PCR fragments as tDNA were checked by PCR and sequencing. 


\subsection{Pneumococcal Strain Constructions}

\subsection{1. $\operatorname{rec} A, \operatorname{rec} O, \operatorname{rec} R, \operatorname{rec} F$, and $\operatorname{rexB}$ Strains}

The $\operatorname{rec} A^{-}$R3309 strain was constructed by transformation of the R825 strain with genomic DNA of the R209 strain that contains the $r e c A:: c m$ allele. The $\mathrm{recO}^{-}$strain $\mathrm{R} 2411$ was constructed by transformation of the R895 strain with genomic DNA of the R2372 strain that contains the recO:: $s p c^{13 C}$ allele (Johnston et al. 2015). The recR ${ }^{-}$strain R2412 was constructed by transformation of the R895 strain with genomic DNA of the R2373 strain that contains the recR:: $k_{a n}{ }^{15 C}$ allele (Johnston et al. 2015). The rexB ${ }^{-}$strain R4036 was constructed by transformation of the R825 strain with genomic DNA of the DPH14 strain that contains the rexB:: spc allele [20].

\subsubsection{CEP-P lac $_{\text {: }: y a b A}$ Strain}

The CEP-P lac ::yabA strain (R3319) derives from the R895 and R3310 strains. The R3310 strain comprises the Chromosomal Expression Platform (CEP)- $\mathrm{P}_{\text {lac }}$, which is inserted at the amiF locus and is composed of a Kn-resistance gene, the lacI gene, the IPTG-inducible $\mathrm{P}_{l a c}$ promoter, and the $l u c$ coding sequence as previously described [21]. The CEP-Plac::yabA (R3319) strain was generated by transforming the R895 strain with a SOEing PCR product composed of the CEP-P $P_{\text {lac }}::$ yabA sequence framed by the amiF-lacI-Plac and kan-treP sequences and obtained from the three PCR products: amiF-lacI-Plac (primers OVK134 and OVK169 using R3310 genomic DNA as a template), yabA (primers OVK229 and OVK230 using R895 genomic DNA as a template), and kan-treP (primers OVK172 and OVK139 using R3310 genomic DNA as a template).

\subsubsection{CEP-P $\mathrm{P}_{\text {lac }}:$ dnaA Strain}

The CEP-P ${ }_{\text {lac }}::$ dnaA strain (R3318) was obtained by transformation of the R895 strain

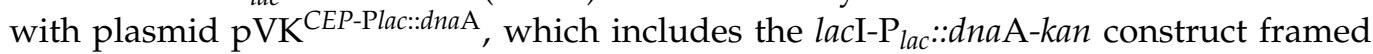
by $a m i \mathrm{~F}$ and treP sequences constructed by the SOEing with the pUC19 plasmid backbone. This plasmid derives from the plasmid $\mathrm{pVK}^{\mathrm{CEP}-\mathrm{Plac}: \mathrm{I}-\mathrm{sceI}}$ constructed as follows: first, a CEP-P lac :I-sceI strain (R3312) was constructed by transformation of R825 with $a$ SOEing-PCR fragment assembled from three PCR products corresponding to amiF-lacI$P_{\text {lac }}$ (primers OVK134 and OVK169 and genomic DNA from R3310 as a template), I-sceI (primers OVK170 and OVK208 and plasmid pUC19-I-SceI as a template), and kan-treP (primers OVK172 and OVK139 using genomic DNA of R3310 as a template (the I-sceI coding sequence was synthesized with codons optimized for S. pneumoniae as defined by the OptimumGene ${ }^{\mathrm{TM}}$ algorithm and cloned into the pUC19 vector by Genscript USA to generate plasmid pUC19-I-sceI); second, a PCR fragment corresponding to CEP-P $\mathrm{Pac}_{\text {la }}: \mathrm{I}-$ sceI (primers OVK301 and OVK304 using genomic DNA from R3313 strain) digested PstI/EcoRI was cloned into pUC19 ${ }^{(\mathrm{NdeI})}\left(\mathrm{pUC19}{ }^{(\mathrm{NdeI})}\right.$ is a pUC19 derivative mutated for its NdeI site); third, to generate the $\mathrm{pVK} \mathrm{CEP}^{\mathrm{CElac}:: d n a \mathrm{~A}}$ plasmid, a PCR fragment encompassing dnaA coding sequence, generated with OVK214 and OVK3 primers and using R895 as a template, was digested by NdeI and BamHI and substituted for the I-SceI coding sequence into pVK ${ }^{\text {CEP-Plac::I-sceI }}$ digested by NdeI and BamHI.

${ }^{e} \mathrm{P}_{\text {lac }}::$ dnaA, ${ }^{\mathrm{e}} \mathrm{P}_{\text {lac }}::$ dnaE, and ${ }^{\mathrm{e}} \mathrm{P}_{\text {lac }}:$ dnaC Strains

To construct these strains, we first designed a construct allowing the targeted insertion of the $\mathrm{P}_{\text {lac }}$ promoter at any endogenous locus of the pneumococcal chromosome and defined as ${ }^{\mathrm{e}} \mathrm{P}_{\text {lac }}$ hereafter (with ${ }^{\mathrm{e}}$ indicating endogenous). This construct derived from the CEP-P lac ::luc ectopic construct of the R3110 strain [21], with a Spc-resistance gene (aad9) substituting the Kn-resistance gene to give the R3311 strain. This substitution was achieved by transformation of the R3110 strain with a SOEing-PCR product between three PCR products corresponding to lacI (primers OVK136 and OVK213 using genomic DNA of R3310 as a template), aad9 (primers OVK210 and OVK28 on plasmid pR412 [22], and $P_{\text {lac }}:: l u c$ (primers OVK214 and OVK215 using genomic DNA of R3310 as a template), as well as selecting for $\mathrm{Spc}^{\mathrm{R}} \mathrm{Kn}^{\mathrm{S}}$ clones. 
The ${ }^{\mathrm{e}} \mathrm{P}_{\text {lac }}:$ :dnaA strain (R3317) was obtained by transformation of R895 with a SOEing PCR fragment generated from three overlapping PCR products made of the $5^{\prime}$-dnaA sequence (primers OVK196 and OVK218 using genomic DNA of R895 as a template), the lacI and $\mathrm{P}_{\text {lac }}$ promoter sequences up to the ATG initiation codon (primers OVK136 and OVK169 using genomic DNA of R3311 as a template), and the dnaA coding sequence (primers OVK219 and OVK199 using genomic DNA of R895 as a template), as well as selection for Spc ${ }^{\mathrm{R}}$ clones. Of note, the natural TTG start codon of $d n a A$ has been maintained in this synthetic construct and is preceded by the ATG codon from the $\mathrm{P}_{\text {lac }}$ promoter.

The ${ }^{e} \mathrm{P}_{\text {lac }}::$ dnaC (R3316) strain was obtained by transformation of R895 with a SOEing PCR product generated from three overlapping PCR products made of the $5^{\prime}-d n a C$ sequence (primers OVK245 and OVK246 using genomic DNA of R895 as a template), the lacI and $\mathrm{P}_{\text {lac }}$ promoter sequences up to the ATG initiation codon (primers OVK136 and OVK237 using genomic DNA of R3311 as a template), and the dnaC coding sequence (primers OVK247 and OVK248 using genomic DNA of R895 as a template).

The ${ }^{\mathrm{e}} \mathrm{P}_{\text {lac }}:$ :dnaE (R3315) strain was constructed by transformation of R895 with a SOEing-PCR product generated from three overlapping PCR products made of the $5^{\prime}-d n a E$ sequence (primers OVK251 and OVK252 using genomic DNA of R895 as a template), the lacI and $\mathrm{P}_{\text {lac }}$ promoter sequences up to the ATG initiation codon (primers OVK136 and OVK237 using genomic DNA of R3311 as a template), and the dnaE sequence (primers OVK256 and OVK254 using genomic DNA of R895 as a template). Of note, an extra sequence of seven nucleotides was found inserted between the Shine-Dalgarno and the ATG of the $\mathrm{P}_{\text {lac }}$ promoter in this synthetic ${ }^{e} \mathrm{P}_{l a c}::$ dnaE construct.

These $\mathrm{Spc}^{\mathrm{R}}$ strains were selected on solid THY medium (Thodd Hewitt broth supplemented with $2 \%$ yeast extract (Difco)) supplemented by IPTG $(10 \mu \mathrm{M})$. Next, clones were screened for their IPTG dependency for growth, and the genomic region encompassing the fused PCR fragments was fully sequenced.

\section{3. ori/ter Ratio Measurement}

Genomic DNAs were prepared using a DNeasy DNA extraction kit (Qiagen). Quantitative realtime PCR was performed on a Realplex thermocycler device using Sybergreen dye (iQ SYBR Green Supermix, Biorad, Hercules, CA, USA) to amplify specific origin or terminus sequences. Oligonucleotides used for PCR amplification were chosen by using the 'eprimer3' program (http:/ / bioweb.pasteur.fr (accessed on 27 Feburary 2013)). The amplified origin sequence corresponds to a 129-bp-long PCR product obtained by using primers OVK36 and OVK37 that target the 7594-7722 region of the S. pneumoniae chromosome (Figure S2). The terminus sequence is a 125-bp-long PCR product obtained by using primers OVK46 and OVK47 that amplify the 1,046,843-1,046,967 region of the S. pneumoniae chromosome (Figure S2). These two pairs of primers, defined as ori and ter, respectively, exhibited $98 \%$ amplification efficiency. The ori/ter ratio was measured at different time points of the cell growth as indicated in the text and/or in the legend of the figures. Each ori/ter measurement was performed using at least two independent cell cultures.

\section{Results}

\subsection{RecA-Mediated Recombination Prevents Competence Development in S. pneumoniae}

To compare competence development in wild-type (WT) and recA mutant $\left(r e c A^{-}\right)$ strains, we monitored the expression of a competence-induced gene $(\operatorname{com} C)$ fused to the firefly luciferase gene, as reported previously ([17]; see Material and methods). In this assay, light emitted by the growing cells is recorded in real time as relative luminescence units (RLU) normalized to cell density expressed as $\mathrm{OD}_{492}$ (see Material and methods; Figure 1A). Under conditions appropriate for competence development, this gives rise to a characteristic, transient peak of competence gene expression during exponential growth. This expression, and competence development itself, declines progressively as the initial $\mathrm{pH}$ of the medium used is acidified (Figure S1; $[23,24]$ ). Conditions that stimulate or depress competence induction, such as certain mutations and drugs, can overcome the $\mathrm{pH}$ 
effect and thus cause the return or disappearance of the expression peak, changes termed hereafter competence-up ('cup') and competence-down ('cdo') phenotypes, respectively. We observed that a recA- mutant exhibits a cup phenotype, as it develops spontaneous competence at a $\mathrm{pH}$ at which the WT strain does not (Figure 1B). This result implies that the RecA protein impedes pneumococcal competence development.

As pneumococcal competence is known to be induced by various types of DNA damage $[13,15]$, the cup phenotype of the recA strain could stem from types of damage that are no longer efficiently corrected by RecA recombination activity. RecA-mediated maintenance of genome integrity is known to proceed by distinct recombination pathways, triggered by distinct types of damage and involving specific sets of effectors [25-27]. Early effectors of these pathways promote the formation of the RecA presynaptic recombination filaments on ssDNA, upon which RecA then executes the DNA strand-exchange reactions that restore the genome. Two distinct recombination effectors are involved in genome maintenance in bacteria. One is the RecF-RecO-RecR triad that acts at DNA gaps [27]; the other is the RecBCD complex in E. coli [27], termed RexAB in S. pneumoniae [20], which acts at double-strand breaks (DSB). To evaluate the relative importance for competence of these two recombinational pathways in S. pneumoniae, we monitored competence induction in $r e c O^{-}$, rec $\mathrm{R}^{-}$, and $r e x \mathrm{~B}^{-}$mutants by recording the expression of a luc transcriptional fusion with the $s s b \mathrm{~B}$ competence gene. Each mutant exhibited a cup phenotype (Figure 1B). These results show that impairment of recombinational pathways that repair the genome is a potential source of competence induction.

\subsection{The Cup Phenotype of the rec $A^{-}$Mutant Is Exacerbated by the DNA Damaging Agent Mytomycin-C in a Dose-Response Manner}

To further verify that the cup phenotype of the rec $\mathrm{A}^{-}$mutant results from a deficiency in repairing genome damage, we compared competence development of WT and $\operatorname{rec} A^{-}$ strains in the presence of increasing amounts of MMC, a DNA damaging agent known to induce pneumococcal competence when added at concentrations impacting growth and cell viability [13]. Here, the $\mathrm{pH}$ of the medium was adjusted to prevent spontaneous competence development in rec $\mathrm{A}^{-}$cells. Under these conditions, competence of the WT strain was readily induced by $\mathrm{MMC}$ at $30 \mathrm{ng} \cdot \mathrm{mL}^{-1}$ and above (Figure 2). Competence was also induced by $\mathrm{MMC}$ in the $\mathrm{recA}^{-}$strain, but at much lower concentrations of the drug (Figure 2). Furthermore, the competence peak of the rec $\mathrm{A}^{-}$strain occurred earlier during growth than for the WT strain at all MMC concentrations tested, concomitant with an increase in the induction level in proportion to MMC concentration. This result is likely to be a consequence of a gradual accumulation of unrepaired DNA lesions that foster competence development. In WT cells, most of these DNA lesions would be efficiently repaired by RecA recombination pathways, avoiding competence development until the extent of damage exceeds the capacity for efficient repair. Thus, these results support the notion that signaling leading to competence induction is a quantitative response, developing in proportion to the damage suffered by the DNA. 


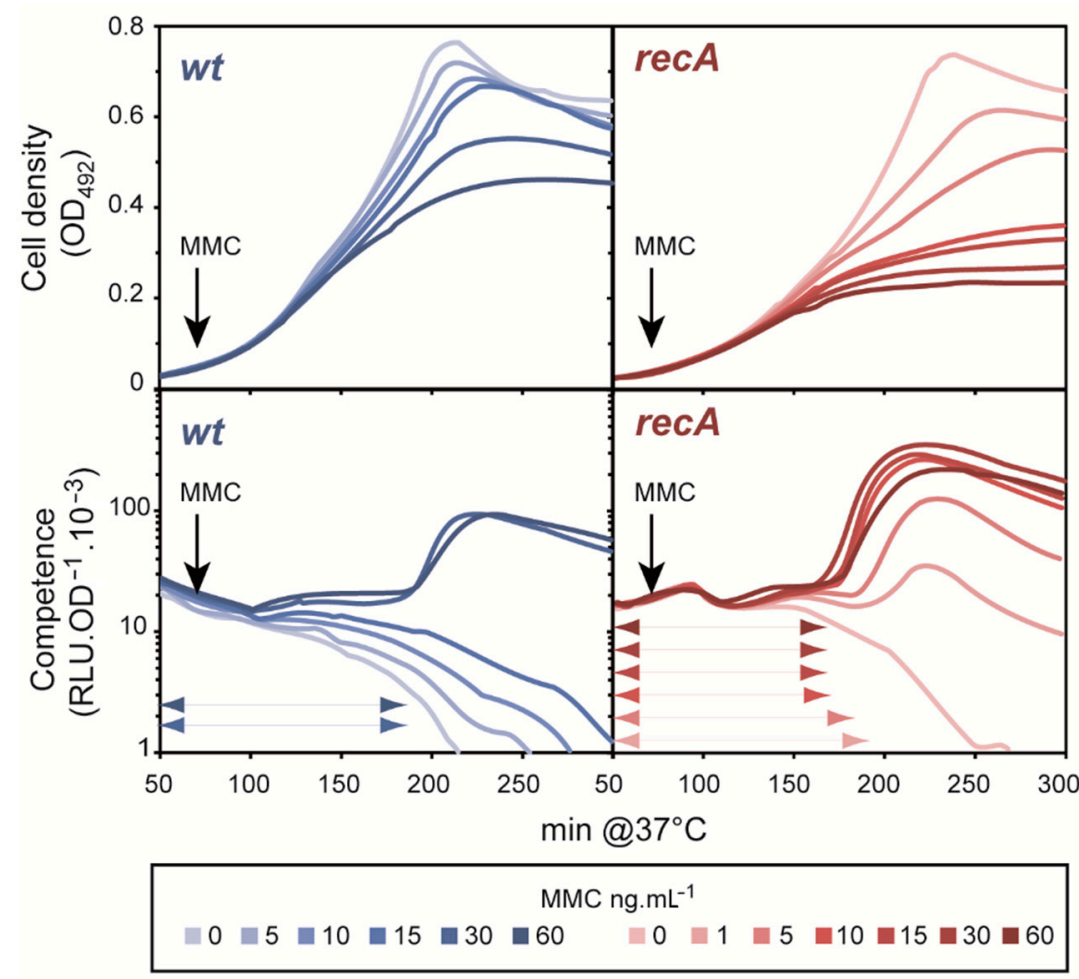

Figure 2. The lack of RecA exacerbates MMC-mediated competence induction. WT and rec ${ }^{-}$ cells were cultivated in $\mathrm{C}+\mathrm{Y}$ medium adjusted to a $\mathrm{pH}$ non-permissive for spontaneous competence development. Cell density $\left(\mathrm{OD}_{492}\right)$ is shown in the upper panels and competence gene expression $\left(\right.$ RLU.OD ${ }_{492}{ }^{-1} \times 10^{3}$ ) in the lower panels recorded every $10 \mathrm{~min}$. After $70 \mathrm{~min}$ of growth, MMC was added at the indicated concentrations, shown as light grey-blue to dark grey-blue for WT cells and light brown to dark brown for $r e c A^{-}$cells. The curves represent the mean of two replicates. Standard deviations are omitted for clarity. Double arrowheads depict the $\mathrm{X}_{\mathrm{A}}$ period.

\subsection{Competence Induction by Replication Inhibitor HPUra Is Independent of Gene Dosage Changes}

Several drugs that inhibit replication have been reported to induce competence in Pneumococcus $[13,15]$. Chromosome replication in S. pneumoniae is initiated bidirectionally from the origin, oriC, situated between the two closely linked competence control operons, $\operatorname{com} \mathrm{CDE}$ and $\operatorname{com} \mathrm{AB}$, and terminates diametrically opposite in the ter $\mathrm{C}$ region (Figure S2). An analysis of transcription levels in cells treated with replication inhibitors suggested that the increased gene dosage of origin-proximal genes resulting from continued initiation on chromosomes with paused replication forks would raise the relative rate of comCDE gene expression enough to activate the ComABCDE positive feedback loop, leading to competence induction [15]. In this study, however, replication drugs were used at only one concentration, leaving open the possibility that other mechanisms might not have come to light.

We explored competence development over a range of concentrations of the replication damaging agent, HPUra, a nucleotide derivative that specifically blocks PolC polymerase progression by competing with dGTP [28]. The addition of increasing amounts of HPUra to the WT strain gradually reduced the growth rate of WT cells (Figure 3A). We monitored competence development over this range of HPUra concentrations in a medium adjusted to a $\mathrm{pH}$ that does not allow spontaneous competence development without the drug. Figure $3 \mathrm{~A}$ shows that $s s b B:: l u c$ expression increased steadily with HPUra concentration up to $300 \mathrm{ng} \cdot \mathrm{mL}^{-1}$, at which point the competence of the population was fully developed. We next determined the effect of HPUra concentration on relative oriC gene dosage, by qPCR measurement of the ori /ter ratio (see Figure S2A and Section 2). Figure S2B shows the time course of ori/ter response to addition of HPUra at $50 \mathrm{ng} \cdot \mathrm{mL}^{-1}$ in comparison with 
the ori/ter ratio of cells grown without the drug. In the absence of HPUra, the ori/ter ratio remained constant at 1.6 (Figure S2B), corresponding to the value obtained by sequencing of chromosomal DNA extracted from exponentially growing pneumococcal cells [29]. In the presence of HPUra, the ori/ter ratio gradually increased over time (Figure S2B). Based on this calibration, we measured the ori/ter ratio over the whole range of HPUra concentration, in samples taken at the last time-point in the series (60 min). As shown in Figure $3 \mathrm{~B}$, the correlation between the ori/ter ratio and HPUra concentration broke down above $100 \mathrm{ng} \mathrm{mL}^{-1}$, whereas competence gene expression continued to rise. Indeed, at the highest HPUra concentration $\left(1000 \mathrm{ng} \mathrm{mL}^{-1}\right)$, the ori/ter ratio was nearly identical to that in the absence of drug (Figure 3B) despite inducing the highest level of competence (Figure 3A).
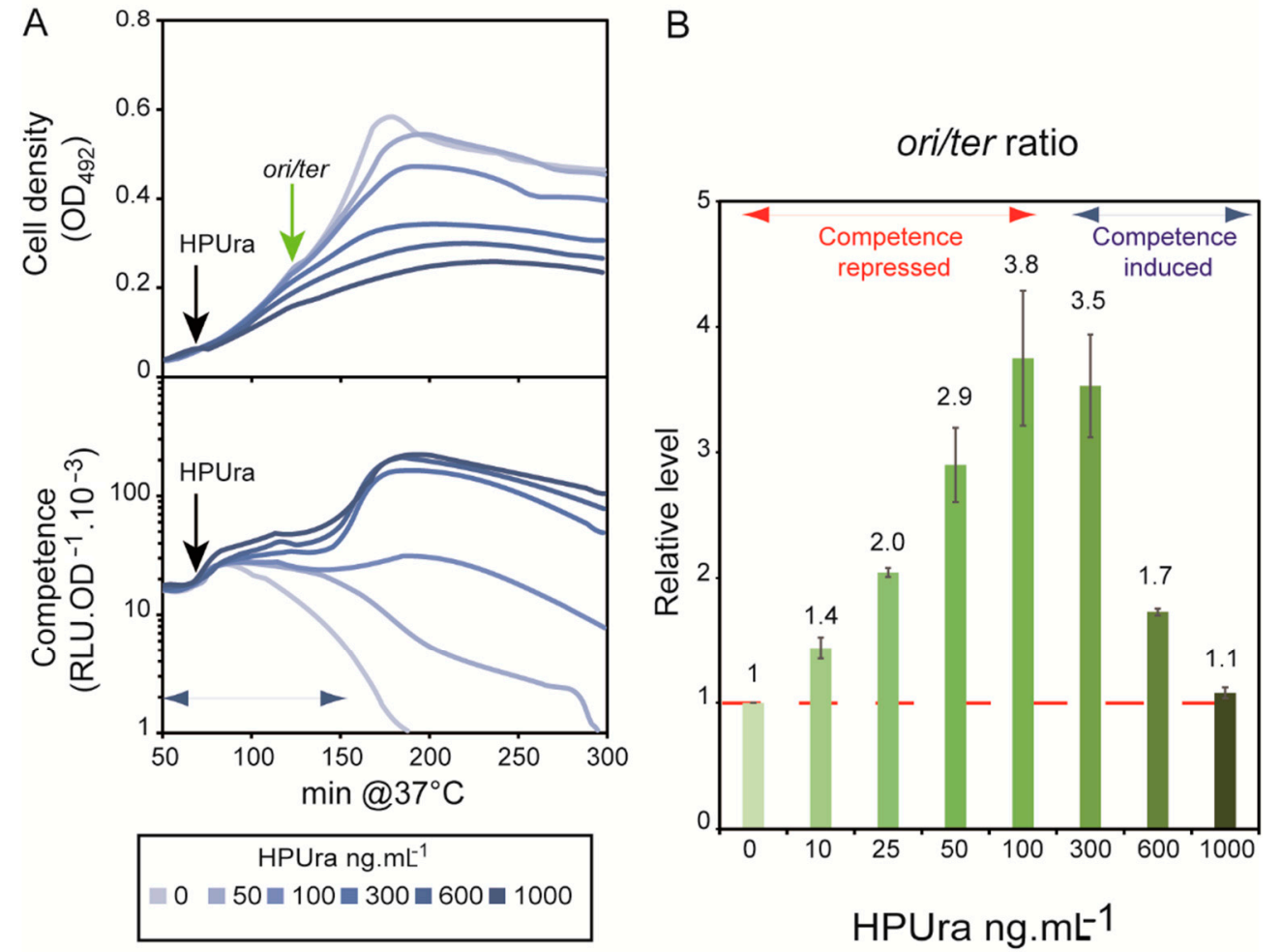

Figure 3. HPUra induces competence independently of its effect on the ori/ter ratio. (A): R895 cells were grown at a $\mathrm{pH}$ non-permissive for spontaneous development of competence. After $70 \mathrm{~min}$ of growth, HPUra was added at 0, 50, 100, 300, 600, and $1000 \mathrm{ng} \mathrm{mL}^{-1}$, light grey-blue to dark grey-blue, respectively. Cell density and competence plots are as in Figure 2. Curves represent the mean of three replicates for each condition. Standard deviations are omitted for clarity. (B): ori/ter ratios measured by qPCR on total DNA extracted from the WT R825 strain $1 \mathrm{~h}$ after HPUra addition at 0, 10, 25, 50, $100,300,600$, and $1000 \mathrm{ng} \mathrm{mL}^{-1}$ (shown as light green to dark green respectively; see also Figure S1). The ori/ter ratio obtained for cells grown without HPUra was set to 1 and used as the reference for ori/ter ratios of cells at each HPUra concentration. The competence development status of each assay is indicated by the blue (induced) and red (basal level) double arrowheads. The means and standard deviations were derived from two replicates.

In light of these results, we also measured the ori/ter ratio of WT cells grown in the presence of increasing amounts of MMC. In this case, the ori/ter ratio increased proportionally with the dose of $\mathrm{MMC}$, with an inducible value of competence development above $40 \mathrm{ng} \cdot \mathrm{mL}^{-1}$ (Figure S2C).

These results show that an increase in the ori/ter ratio resulting from replication impediments, even massive, is not necessarily correlated with induction of competence. This implies that increased com gene dosage at oriC is not a sufficient, or perhaps even 
necessary, signal for competence development. Rather, competence gene expression is readily induced at levels of HPUra that provoke replication fork arrest, as seen by the sharply decreased ori/ter ratio and of growth rate at the highest HPUra concentrations tested. These findings indicate that competence development is poised to respond to disruptions in DNA replication. We further explored this idea by examining the induction of competence in response to other essential replication effectors.

\subsection{Modulation of Competence Development by Altering DnaA Concentration}

DnaA is the widely conserved master regulator of chromosomal DNA replication initiation in bacteria. Its activity is regulated by several mechanisms, some species-specific, which combine to coordinate replication with the cell-cycle. One key parameter known to affect replication in $B$. subtilis is overexpression of $d n a A$ from its native locus, which leads to DNA stresses and ends up in SOS induction [30].

To investigate whether artificial modulation of DnaA concentration in the cell could influence pneumococcal competence development, we replaced the promoter region of $d n a \mathrm{~A}$ with a synthetic IPTG-inducible Plac promoter (see Material and methods). Growth of the resulting ePlac-dnaA strain was IPTG-dependent, as shown by the spot test assay presented in Figure 4A. Cell growth was severely and progressively retarded at $\leq 2.5 \mu \mathrm{M}$ IPTG, and scarcely any colony was detected with none. Above $5 \mu \mathrm{M}$ IPTG, colonies were identical in shape and number to those of the WT, but at the highest IPTG concentration tested $(100 \mu \mathrm{M})$, colonies appeared smaller, indicating that $d n a \mathrm{~A}$ overexpression is detrimental to the cell cycle. The measured ori/ter ratios were correlated with colony-forming ability: oriC was under-replicated below $2.5 \mu \mathrm{M}$ IPTG, replicated at WT frequency at 5-10 $\mu \mathrm{M}$, and over-replicated at $100 \mu \mathrm{M}$ (Figure 4C). We then analyzed competence development in the $\mathrm{e}$ Plac-dnaA strain grown in liquid medium with this range of IPTG concentrations and at different $\mathrm{pH}$ values. Cells grown at the highest $d n a \mathrm{~A}$ expression level exhibited a cup phenotype in comparison with cells grown between 5 and $10 \mu \mathrm{M}$ IPTG (Figure 4B). In contrast, when grown in competence-permissive medium to allow a more graded observation of competence response, the e Plac-dnaA strain developed competence later and less strongly at inducer concentrations below $2.5 \mu \mathrm{M}$ than when induced at levels enabling normal growth $(5-10 \mu \mathrm{M})$. We also noted that the $\mathrm{X}_{\mathrm{A}}$ time taken to induce competence gradually decreased between 2.5 and $10 \mu \mathrm{M}$, while the ori/ter ratio was effectively constant (Figure 4B). These results point to a correlation between the dnaA expression level and the tendency of cells to develop competence, independently of relative gene dosage.

The $d n a \mathrm{~A}$ gene is the first gene of an operon whose second gene is $d n a \mathrm{~N}$, which encodes the DNA polymerase processivity factor of the replisome [30]. Consequently, DnaN concentration will also be modulated by IPTG concentration in the ePlac-dnaA strain, and this in turn could impact replication and the propensity of the cells to develop competence. Indeed, inhibition of DNA synthesis in B. subtilis by overproduction of DnaA was shown to result from DnaA-mediated repression of the $d n a \mathrm{~A}-d n a \mathrm{~N}$ operon and the consequent depletion of the DnaN protein [30]. Accordingly, we performed the same experiment in S. pneumoniae to explore how over-expression of DnaA alone affects competence development. We inserted an IPTG-inducible Plac-dnaA construct at an ectopic position on the chromosome (see Section 2). The resulting CEP-Plac-dnaA strain was grown with $100 \mu \mathrm{M}$ IPTG in a medium adjusted to a $\mathrm{pH}$ non-permissive for competence development without IPTG. As shown in Figure S3, DnaA over-expression readily induced competence and also hindered growth more severely than in the case of the ${ }^{\mathrm{e}} \mathrm{Plac}-\mathrm{dna \textrm {A }}$ strain at the same IPTG concentration (see Figure 4B). Thus, increasing the concentration of DnaA itself induces competence development. 
A
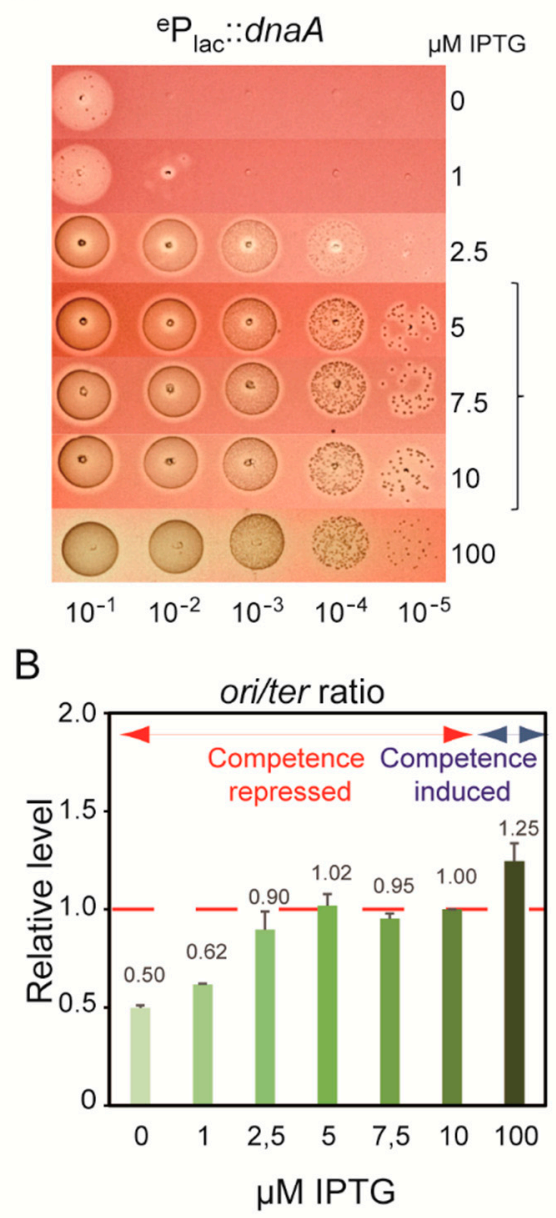

C

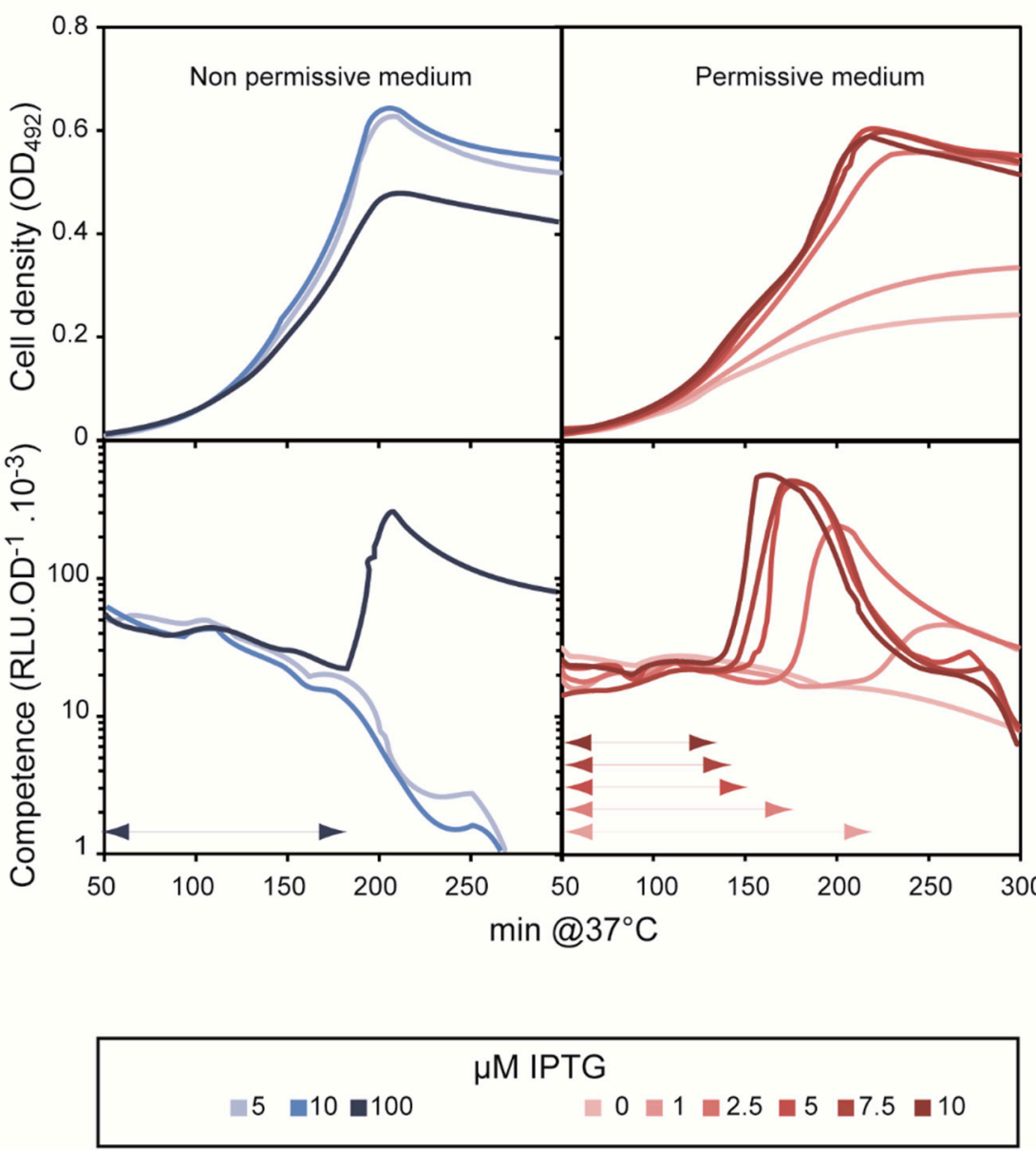

Figure 4. Differential control of competence development by modulated $d n a A$ expression. In strain R3317, the endogenous dnaA promoter has been replaced by the inducible $\mathrm{P}_{l a c}$ promoter $\left({ }^{e} \mathrm{P}_{l a c}:: d n a A\right.$, see Section 2). (A): Growth assay. R3317 cells were grown to OD550 $=0.3$ and were serially diluted and spotted on plates containing the indicated IPTG concentrations. The bracket covers IPTG concentrations enabling the mutant to mimic WT growth. (B): ori/ter ratios measured by qPCR on total DNA extracts from the R3317 strain $\left({ }^{e} P_{l a c}:\right.$ dnaA $)$ cultivated at the indicated IPTG concentrations and normalized to the ori/ter ratio of cells grown with $10 \mu \mathrm{M}$ IPTG. The latter ratio also corresponds to the ori/ter ratio of the isogenic WT strain (red horizontal dotted line). The competence development status of each assay is indicated by the blue (induced) and red (repressed) double arrowheads (see Material and methods). The means and standard deviations were based on two replicates. (C): Growth (upper graphs) and competence gene expression (lower graphs) of the ${ }^{e} P_{l a c}:: d n a A$ strain were monitored in media non-permissive (left panels) or permissive (right panels) for competence development of this strain grown at $10 \mathrm{mM}$ IPTG. Double arrowheads specify the $\mathrm{X}_{\mathrm{A}}$ period. Curves represent the mean of two replicates. Standard deviations are omitted for clarity.

We then investigated the $c d o$ phenotype shown by the ePlac-dnaA strain upon growth without IPTG (Figure 4B). For this, we used a (S. pneumoniae) strain overproducing a close homologue of the B. subtilis YabA protein, which has been demonstrated to down-regulate replication initiation at oriC by interacting with DnaA [31-33]. Importantly, B. subtilis YabA has been shown not to interfere with transcriptional regulation by DnaA [34]. As shown in Figure S4, we found that IPTG-induced expression of pneumococcal YabA from an ectopic Plac-yabA construct led to a $c d o$ phenotype. This result strongly supports the notion that a reduced rate of DnaA-mediated replication initiation at oriC depresses spontaneous competence development. This $c$ do phenotype could stem from diminished expression of the com $\mathrm{CDE}$ operon, resulting from reduction of the ori/ter ratio due to altered timing of replication from oriC. To explore this possibility, we determined whether ePlac-dnaA cells 
grown without IPTG could develop competence upon addition of synthetic CSP to the growth medium. As shown in Figure S5, CSP added at any time during growth led to immediate induction of competence in ${ }^{\mathrm{e}} \mathrm{Plac}-\mathrm{dna}$ A cells cultivated without IPTG or with $5 \mu \mathrm{M}$ IPTG (in a medium of $\mathrm{pH}$ not permitting spontaneous competence development in the latter case). This indicates that DnaA-depleted cells maintained ComD and ComE basal levels above the threshold needed for CSP sensing and competence induction.

Taken together, these results support the idea of a cause-and-effect relationship between DnaA concentration and spontaneous development of pneumococcal competence. They also indicate that the relationship is based on the rate of initiation from oriC rather than on the regulatory properties of DnaA.

\subsection{Aborted Replicative DNA Synthesis Fosters Competence Development}

The experiments until this point revealed that alterations in the active concentrations of PolC and DnaA influenced spontaneous competence development. Previous experiment with HPUra revealed that reducing the active concentration of PolC resulted in a cup phenotype, most probably as a consequence of replication fork arrest and/or collapse. To delve further into this correlation, we used the same approach to examine the consequences of varying availability of the replicative helicase DnaC [35] and the replisome polymerase DnaE [36,37], both being essential for cell viability. In B. subtilis, DnaC and DnaE intervene, in that order, prior to DnaN and PolC in the assembly of replication forks at oriC and in re-initiation at interrupted forks, respectively [38]. Thus, depletion of either enzyme is expected to severely impede replication, at the initiation and the elongation steps, in both cases leading to the accumulation of arrested forks. We constructed two strains to enable IPTG-dependent modulation of $d n a \mathrm{C}$ and $d n a \mathrm{E}$ expression at their native chromosomal loci. As expected, growth of these strains was IPTG-dependent (Figures 5A and 6A). Notably, however, depletion of these proteins was not complete, as inferred from the increase in the cell density of cultures even without IPTG (Figures 5B and 6B). Growth under these conditions below $1 \mu \mathrm{M}$ IPTG was, however, not sufficient to generate visible colonies in solid medium (Figures 5A and 6A). To measure spontaneous competence development in these strains over a range of IPTG concentrations, we used cells initially cultured at an IPTG concentration permitting WT growth rate and the ori/ter ratio and at a $\mathrm{pH}$ preventing induction of competence. Under these conditions, both the ${ }^{\mathrm{e}} \mathrm{Plac}-d n a \mathrm{E}$ and ${ }^{\mathrm{e}} \mathrm{Plac}-d n a \mathrm{C}$ strains exhibited a cup phenotype when grown below $1 \mu \mathrm{M}$ IPTG (Figures 5B and 6B). The ori/ter ratio increased slightly in the ePlac-dnaE strain under these conditions (Figure 5C). In stark contrast, the ori/ter ratio fell markedly in the ${ }^{\mathrm{e}}$ Plac-dnaC strain grown below $1 \mu \mathrm{M}$ IPTG (Figure 6C), i.e., under the conditions leading to competence development.

Taken together, these results reinforce the notion that replication fork arrest and collapse are major triggers of competence development in S. pneumoniae.

\section{Discussion}

In this study, we have investigated the causal relationship between damage to the integrity or replication of the genome and competence induction in S. pneumoniae. We observed that deficiencies in RecA-directed repair stimulated competence development and conclude that competence induction stems from the sensing of injuries that are continuously generated during growth but normally repaired. Interestingly, competence in Helicobacter pylori, recorded by transformation efficiency, was reported to be improved in DNA repair mutants [39]. Recombinational DNA repair pathways are known to buttress chromosomal DNA replication by promoting the rescue of damaged forks via mechanisms that differ according to the type of injury suffered $[27,40]$. Thus, the cup phenotype of the recA, recO, recR, and rexA mutants would reflect their failure to efficiently repair damage at replication forks (Figure 1B). Supporting this proposal, a cdo phenotype appears upon inhibition of DnaA-mediated initiation (by overexpression of the YabA replication repressor; Figure S4): the lower initiation rate would reduce the frequency of forks and hence of fork failure and the signals triggering competence. Failure of repair was not the only source of damage 
signals: increasing damage frequency by addition of replication inhibitors, such as MMC and HPUra, also accelerated competence development. Common to all the disruptions of replication that lead to competence development are unrepaired replication forks.

A

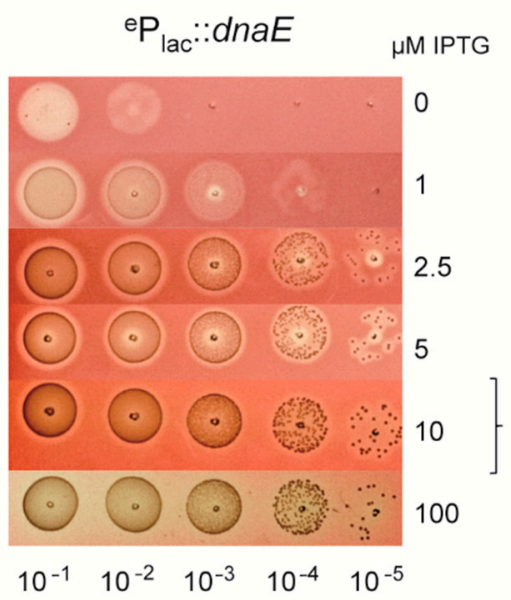

B

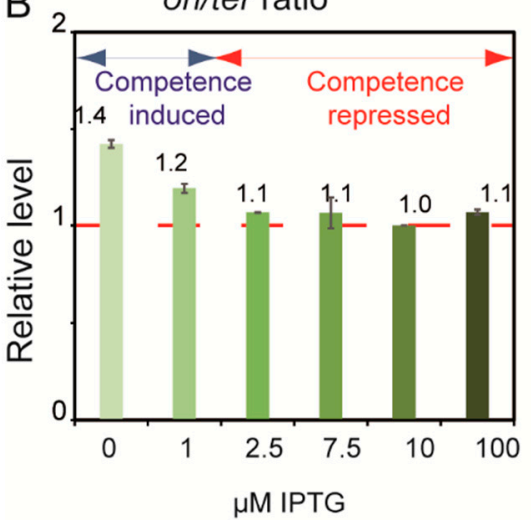

C

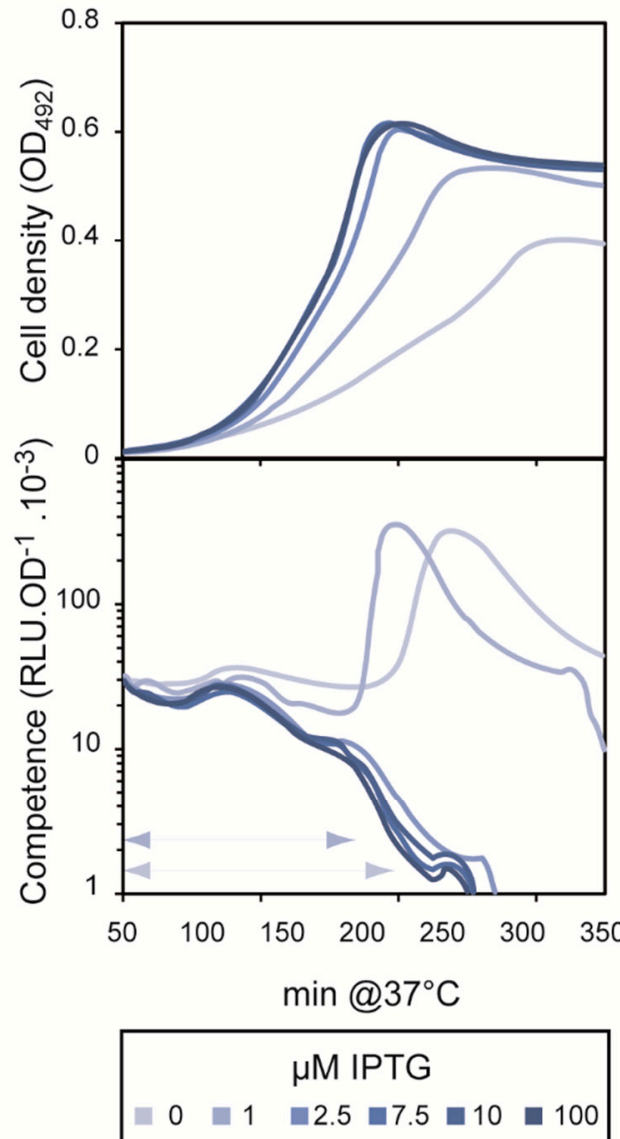

Figure 5. Reduction of $d n a E$ expression induces competence. In strain R3315, the endogenous $d n a E$ promoter has been replaced by the inducible $\mathrm{P}_{l a c}$ promoter ( ${ }^{\mathrm{e}} \mathrm{P}_{l a c}:: d n a E$, see Section 2). (A): Growth assay. R3315 cells were grown to $\mathrm{OD}_{550}=0.3$ and then diluted and spotted on medium containing the indicated IPTG concentrations. The bracket covers IPTG concentrations enabling the mutant to mimic wt growth. (B): ori/ter ratios measured by qPCR on total DNA extracted from the R3315 strain ( $\left.{ }^{(} \mathrm{P}_{l a c}:: d n a E\right)$ cultivated at the indicated IPTG concentrations. The ori/ter ratio obtained for cells grown with $10 \mu \mathrm{M}$ IPTG was used as the reference ratio to calculate the relative level (y-axis); it corresponds to the ori/ter ratio of the isogenic WT strain (red horizontal dotted line). The relative ori/ter ratio at each IPTG concentration is indicated, with standard deviations: values are the means of two replicates. The competence development status of each assay is indicated by the blue (induced) and red (repressed) double arrows. (C): Competence expression of the $s s b B:: l u c$ transcriptional fusion in $\mathrm{R} 3315$ was monitored in $\mathrm{C}+\mathrm{Y}$ medium adjusted at an initial $\mathrm{pH}$ non permissive for competence development when cells are cultivated with $10 \mu \mathrm{M}$ IPTG, which fully complemented growth as WT cells. Curves represent the mean of four replicates for each growth condition performed at the indicated IPTG values. Standard deviations are omitted for clarity. Double arrowheads specify the $\mathrm{X}_{\mathrm{A}}$ period. 
A
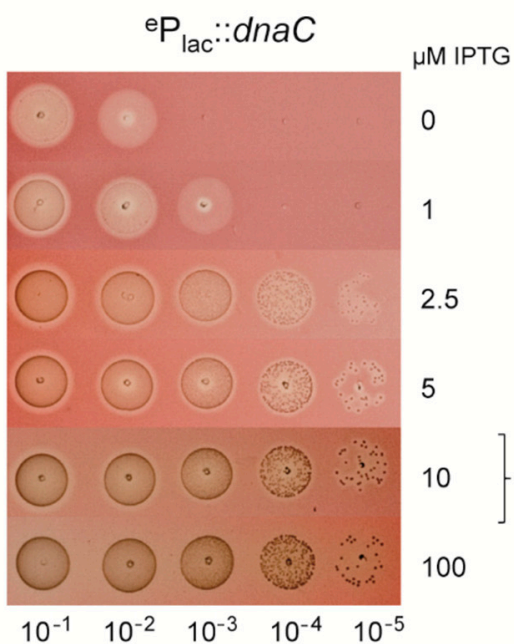

B

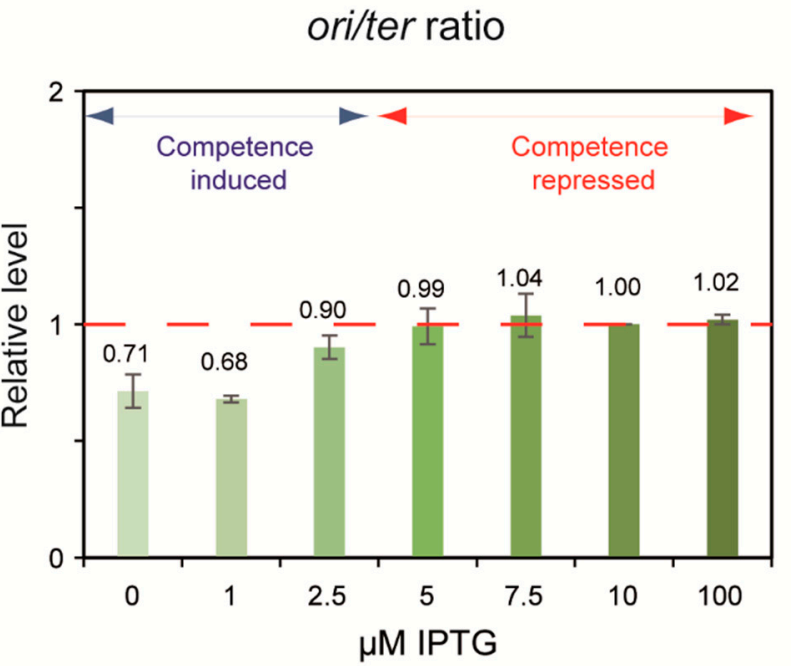

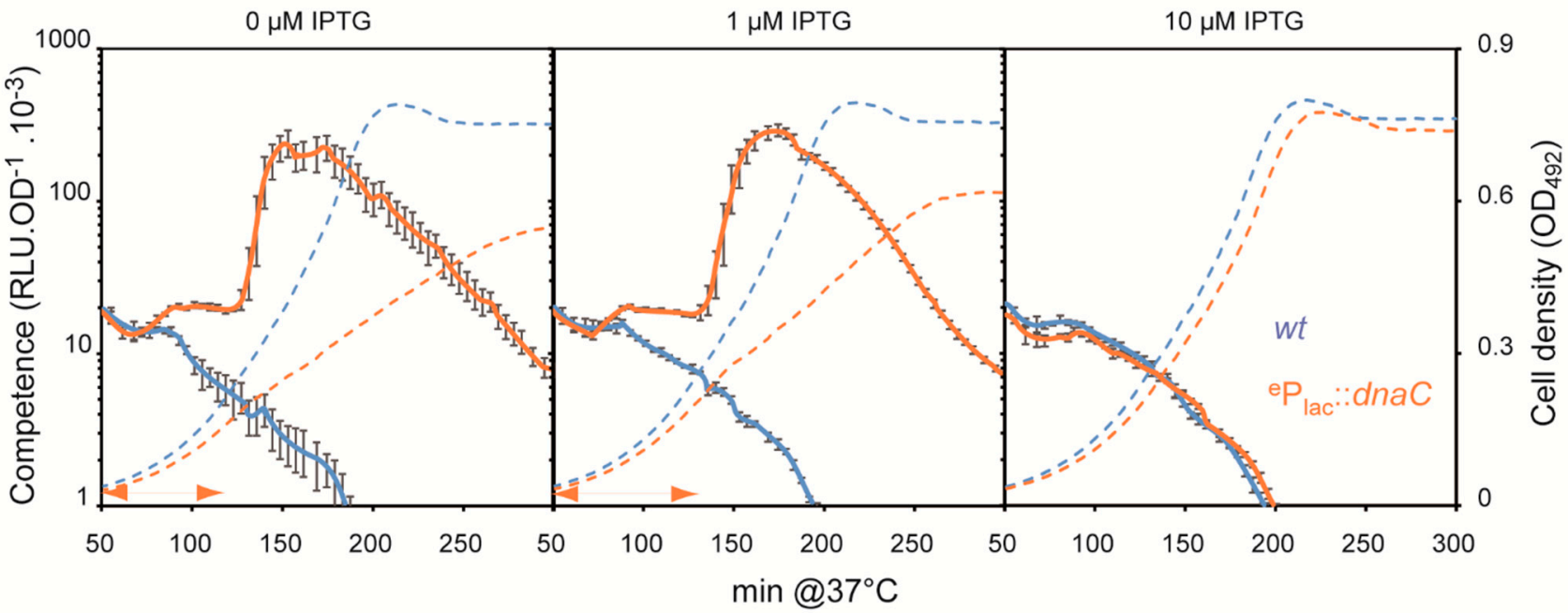

Figure 6. Reduction of $d n a C$ expression induces competence and decreases the ori/ter ratio. In strain R3316, the endogenous dnaC promoter has been replaced by the inducible $\mathrm{P}_{\text {lac }}$ promoter ( ${ }^{\mathrm{e}} \mathrm{P}_{\text {lac }}:$ :dnaC, see Section 2$)$. (A): Growth assay. R3316 cells were serially diluted and spotted on medium containing the indicated IPTG concentrations. The bracket covers IPTG concentrations enabling the mutant to mimic WT growth. (B): ori/ter ratios measured by qPCR on total DNA extracted from the R3316 strain ( ${ }^{e} \mathrm{P}_{l a c}::$ dnaC) cultivated at the indicated IPTG concentrations. The ori/ter ratio obtained for cells grown with $10 \mu \mathrm{M}$ IPTG was arbitrarily set to 1 and used as a reference ratio (relative level), which corresponds to the ori/ter ratio of the isogenic WT strain (red horizontal dotted line). The relative ori/ter ratio measured in each condition is indicated. The competence development status of each assay is indicated by the blue (induced) and red (repressed) double arrows lines. The mean and standard deviation were generated from two replicates. (C): Expression of the $s s b B:: l u c$ transcriptional fusion in the WT strain R895 (blue) and its isogenic ${ }^{e} \mathrm{P}_{l a c}::$ dnaC strain R3316 (orange). Cell density $\left(\mathrm{OD}_{492}\right)$ is presented as dotted lines and competence (RLU.OD $492^{-1} \times 10^{3}$ ) as plain lines recorded every $5 \mathrm{~min}$. Cells were cultivated at $37^{\circ} \mathrm{C}$ in $\mathrm{C}+\mathrm{Y}$ medium with 0,5 or $10 \mu \mathrm{M}$ IPTG at a pH non-permissive for spontaneous development of competence for R3316 grown with $10 \mu \mathrm{M}$ IPTG (as well as for the isogenic WT strain). Double arrowheads specify the $\mathrm{X}_{\mathrm{A}}$ period.

\subsection{How Does Replication Stress Induce Competence?}

Previous studies that linked replication stress to pneumococcal competence induction used exogenous drugs to specifically alter either a replication protein, the dNTP pool, or DNA integrity $[13,15]$. Among these drugs, the most specific for the replication process is HPUra, which effectively reduces the concentration of active replisomal PolC DNA polymerase in a dose-response manner. Here, we constructed strains that express the DnaC helicase and the DnaE DNA polymerase of the replisome in proportion to the concentration 
of added IPTG. The diminution of the active pool of DnaC and of DnaE molecules led to the induction of competence, mirroring the effect of high concentrations of HPUra on WT cells (Figures 3, 5 and 6).

It was previously proposed that the replication defect caused by HPUra was converted into a competence-inducing signal as a consequence of the higher relative dosage of the ori-proximal com $\mathrm{CDE}$ operon resulting from deceleration of the replication forks. HPUratreated cells were shown to express the com $\mathrm{CDE}$ operon at higher levels than untreated cells, and this was proposed to activate the ComABCDE positive feedback loop and turn on competence [15]. A central parameter of this mechanism is the ori/ter ratio, which should increase under replication stress and be correlated with competence induction. We found instances in which this correlation does not hold. An extreme case was that of the ePlac-dnaC strain, which exhibited a cup phenotype when grown with concentrations of IPTG at which the ori/ter ratio gradually declined (Figure 6). Indeed, the ori/ter ratio varied for each replication stress and was not correlated with the propensity of the cells to develop competence. Thus, a high ori/ter ratio, $>3$, was found with HPUra at $50 \mathrm{ng} \cdot \mathrm{mL}^{-1}$, which, however, was not followed by competence induction (Figure 3). By contrast, almost no change in the ori/ter ratio was found for WT cells grown with $1000 \mathrm{ng} \cdot \mathrm{mL}^{-1}$ HPUra (Figure 3) or for the ePlac-dnaE cells grown without IPTG (Figure 5), although competence was readily induced in both situations. Thus, rather than increased comCDE gene dosage and expression, the factor common to all situations of replication stress that foster competence induction was the arrest of replication forks.

In several cases, the propensity of the cells to develop competence was found to be proportional to the intensity of the stress applied. The gradualness of the response was manifested by a change in timing of competence induction, i.e., the more stress, the shorter the period $\left(\mathrm{X}_{\mathrm{A}}\right)$ preceding the peak of expression of competence genes. This was observed in experiments with increasing concentrations of MMC applied to rec $A^{-}$cells (Figure 2), and to ${ }^{\mathrm{e}} \mathrm{Plac}-d n a \mathrm{E}$ and ${ }^{\mathrm{e}} \mathrm{Plac}-d n a \mathrm{C}$ cells grown with $1 \mu \mathrm{M}$ and $0 \mu \mathrm{M}$ IPTG (Figures 5 and 6). Importantly, this dose-response effect should be considered in the light of the two-phase development of competence in pneumococcal populations and the mechanism underlying its coordination between cells. We previously provided genetic evidence that competence of a pneumococcal population develops in a self-activating (autocrine) stage, followed by a wholesale propagation (paracrine) stage (Figure 1A; [9]). During the initial phase, there is a steady increase in the number of individual cells that undergo physiological stress of a kind that induces the ComABCDE feedback loop. When the fraction of such cells rises to a certain level, CSP-mediated induction of neighboring cells through cell-to-cell contact becomes frequent enough to thrust the population into the second phase where competence spreads throughout, as seen by a peak upon monitoring of competence gene expression. The proportional response of competence induction to replication stress reported here is readily explained in this scenario. Lowering IPTG concentrations in cultures of ePlac$d n a \mathrm{E}$ and ${ }^{\mathrm{e}} \mathrm{Plac}-d n a \mathrm{C}$ strains would be expected to progressively reduce DnaE and DnaC levels and increase the frequency of fork stalling. The fraction of individual cells that switch to competence would thus rise faster, leading to the shorter $\mathrm{X}_{\mathrm{A}}$ periods observed. Similarly, addition of increasing amounts of MMC to $\mathrm{rec} A^{-}$cells will raise the fraction of cells accumulating unrepaired damaged DNA, thus progressively reducing the period of competence development (Figure 2). Notably, this gradual response is not observed for WT cells treated with the same range of MMC concentrations (Figure 2). In this case, recombinational repair is fully active up to a limit of the MMC concentration above which competence is induced, reflecting a saturation of repair capacity and leading to a maximal $\mathrm{X}_{\mathrm{A}}$ value. The same reasoning applies to ${ }^{\mathrm{e}}$ Plac-dnaA cells grown at low IPTG concentrations. A gradual reduction of the replication initiation rate at oriC resulted in an extended $\mathrm{X}_{\mathrm{A}}$ period of spontaneous competence development (Figure 4). The same effect was obtained with WT cells by overexpression of the replication inhibitor YabA (Figure S4). In both cases, the gradual diminution of the fraction of cells undergoing active replication exerts a corresponding delay in competence development. 


\subsection{Comparison of Pneumococcal Competence with the SOS Response}

Unlike many bacteria, Pneumococcus does not have an SOS system to respond to DNA damage. Competence, similar to the SOS response, involves the induction a large set of genes that confer altered properties on the cell, but except for a small subset of proteins for DNA repair and recombination, there is little similarity in the competence and SOS regulons. Indeed, recA is the only gene induced in both systems. Nevertheless, our study of competence development in response to DNA damage reinforces the notion that competence is the functional equivalent of SOS. Both systems induce a cell division inhibitor that provides a delay to enable cells to repair DNA breaks before division. In the case of the Pneumococcus, the ComM division inhibitor induced during competence was shown to be crucial for maintaining genome integrity during natural transformation [41]. Competence for transformation itself has been reported to improve survival to exposure to MMC [42], underlining the functional parallel of cell rescue between competence and SOS.

\subsection{Concluding Remarks}

This study focuses on the relationship between the induction of competence in Pneumococcus by replication stress. The underlying signaling mechanism appears not to depend on an increase in the copy number of the oriC-proximal com $\mathrm{CDE}$ operon following replication slowdown, as proposed previously [15]. This leaves open the question of the molecular mechanism that links genome damage to the induction of pneumococcal competence. Aborted replication forks appear to be essential and presumably trigger the signaling pathway that ultimately induces the ComABCDE positive feedback loop. Competence was shown also to be induced in response to genome damage in two other naturally transformable species, Legionella pneumophila and Helicobacter pylori, neither of them encoding a LexA homologue or possessing an SOS system [14]. The regulatory circuit controlling competence in these species is poorly defined, but distinct from the pneumococcal one. Thus, it will be interesting to establish whether a common mechanism leads to competence development in response to genome stress in these species regardless of the particulars of the pathway controlling competence gene expression.

Supplementary Materials: The following are available online at https: / www.mdpi.com/article / 10.3390/cells10081938/s1. Figure S1: Monitoring pneumococcal competence development. Figure S2: Determination of the ori/ter ratio. Figure S3: dnaA overexpression slows growth and induces competence. Figure S4: yabA overexpression represses competence induction. Figure S5: Response to $\mathrm{CSP}$ addition during reduction in $d n a A$ expression. Table S1: Streptococcus pneumoniae strains and primers.

Author Contributions: V.K. and M.P., Conceptualization, Data curation, Formal analysis, Investigation, Methodology, Writing-original draft, P.P. Conceptualization, Investigation, Writing-original draft, review and editing, Supervision, Funding acquisition. All authors have read and agreed to the published version of the manuscript.

Funding: This work was funded by the Agence Nationale de la Recherche (Grants ANR-10-BLAN1331 and ANR-13-BSV8-0022).

Institutional Review Board Statement: Not applicable.

Informed Consent Statement: Not applicable.

Data Availability Statement: All data supporting the findings of this study are available within the article or from the corresponding author upon reasonable request.

Acknowledgments: We particularly thank Dave Lane for critical reading and helpful editing of the manuscript, as well as Mathieu Bergé, Calum Johnston, and Nathalie Campo for their critical reading of the manuscript.

Conflicts of Interest: The authors declare no conflict of interest. 


\section{References}

1. Radman, M. SOS Repair Hypothesis: Phenomenology of an Inducible DNA Repair Which is Accompanied by Mutagenesis. Mol. Mech. Repair DNA 1975, 5A, 355-367. [CrossRef]

2. Witkin, E.M. Ultraviolet mutagenesis and inducible DNA repair in Escherichia coli. Bacteriol. Rev. 1976, 40, 869-907. [CrossRef]

3. Erill, I.; Campoy, S.; Barbé, J. Aeons of distress: An evolutionary perspective on the bacterial SOS response. FEMS Microbiol. Rev. 2007, 31, 637-656. [CrossRef]

4. Claverys, J.-P.; Prudhomme, M.; Martin, B. Induction of Competence Regulons as a General Response to Stress in Gram-Positive Bacteria. Annu. Rev. Microbiol. 2006, 60, 451-475. [CrossRef]

5. Dubnau, D.; Blokesch, M. Mechanisms of DNA Uptake by Naturally Competent Bacteria. Annu. Rev. Genet. 2019, 53, 217-237. [CrossRef]

6. Johnston, C.; Martin, B.; Fichant, G.; Polard, P.; Claverys, J.-P. Bacterial transformation: Distribution, shared mechanisms and divergent control. Nat. Rev. Microbiol. 2014, 12, 181-196. [CrossRef]

7. Johnston, C.; Campo, N.; Bergé, M.J.; Polard, P.; Claverys, J.-P. Streptococcus pneumoniae, le transformiste. Trends Microbiol. 2014, 22, 113-119. [CrossRef]

8. Martin, B.; Soulet, A.-L.; Mirouze, N.; Prudhomme, M.; Mortier-Barrière, I.; Granadel, C.; Noirot-Gros, M.-F.; Noirot, P.; Polard, P.; Claverys, J.-P. ComE/ComE P interplay dictates activation or extinction status of pneumococcal X-state (competence). Mol. Microbiol. 2012, 87, 394-411. [CrossRef]

9. Prudhomme, M.; Berge, M.; Martin, B.; Polard, P. Pneumococcal Competence Coordination Relies on a Cell-Contact Sensing Mechanism. PLoS Genet. 2016, 12, e1006113. [CrossRef]

10. Martin, B.; Granadel, C.; Campo, N.; Hénard, V.; Prudhomme, M.; Claverys, J.-P. Expression and maintenance of ComD-ComE, the two-component signal-transduction system that controls competence of Streptococcus pneumoniae. Mol. Microbiol. 2010, 75, 1513-1528. [CrossRef] [PubMed]

11. Mortier-Barrière, I.; Velten, M.; Dupaigne, P.; Mirouze, N.; Pietrement, O.; McGovern, S.; Fichant, G.; Martin, B.; Noirot, P.; Le Cam, E.; et al. A Key Presynaptic Role in Transformation for a Widespread Bacterial Protein: DprA Conveys Incoming ssDNA to RecA. Cell 2007, 130, 824-836. [CrossRef]

12. Mirouze, N.; Bergé, M.A.; Soulet, A.-L.; Mortier-Barrière, I.; Quentin, Y.; Fichant, G.; Granadel, C.; Noirot-Gros, M.-F.; Noirot, P.; Polard, P.; et al. Direct involvement of DprA, the transformation-dedicated RecA loader, in the shut-off of pneumococcal competence. Proc. Natl. Acad. Sci. USA 2013, 110, E1035-E1044. [CrossRef]

13. Prudhomme, M.; Attaiech, L.; Sanchez, G.; Martin, B.; Claverys, J.-P. Antibiotic Stress Induces Genetic Transformability in the Human Pathogen Streptococcus pneumoniae. Science 2006, 313, 89-92. [CrossRef]

14. Charpentier, X.; Polard, P.; Claverys, J.-P. Induction of competence for genetic transformation by antibiotics: Convergent evolution of stress responses in distant bacterial species lacking SOS? Curr. Opin. Microbiol. 2012, 15, 570-576. [CrossRef]

15. Slager, J.; Kjos, M.; Attaiech, L.; Veening, J.-W. Antibiotic-Induced Replication Stress Triggers Bacterial Competence by Increasing Gene Dosage near the Origin. Cell 2014, 157, 395-406. [CrossRef] [PubMed]

16. Mortier-Barrière, I.; Polard, P.; Campo, N. Direct Visualization of Horizontal Gene Transfer by Transformation in Live Pneumococcal Cells Using Microfluidics. Genes 2020, 11, 675. [CrossRef]

17. Prudhomme, M.; Claverys, J.P.; Hakenbeck, R.; Chhatwal, G.S. The Molecular Biology of Streptococci. 2007. Available online: https:/ / scholar.google.com/scholar_lookup?hl=en\&publication_year=2007\&;pages=519-524\&author=M.+Prudhomme\& author=J.P.+Claverys\&title=The+Molecular+Biology+of+Streptococci (accessed on 26 May 2021).

18. Martin, B.; García, P.; Castanié, M.P.; Glise, B.; Claverys, J.P. The recA gene of Streptococcus pneumoniae is part of a competenceinduced operon and controls an SOS regulon. Dev. Boil. Stand. 1995, 85, 293-300.

19. Martin, B.; Prudhomme, M.; Alloing, G.; Granadel, C.; Claverys, J.-P. Cross-regulation of competence pheromone production and export in the early control of transformation in Streptococcus pneumoniae. Mol. Microbiol. 2000, 38, 867-878. [CrossRef]

20. Halpern, D.; Gruss, A.; Claverys, J.-P.; El Karoui, M. rexAB mutants in Streptococcus pneumoniae. Microbiology 2004, 150, $2409-2414$. [CrossRef]

21. Johnston, C.; Mortier-Barriere, I.; Khemici, V.; Polard, P. Fine-tuning cellular levels of DprA ensures transformant fitness in the human pathogen Streptococcus pneumoniae. Mol. Microbiol. 2018, 109, 663-675. [CrossRef]

22. Johnston, C.; Hauser, C.; Hermans, P.W.M.; Martin, B.; Polard, P.; Bootsma, H.J.; Claverys, J.-P. Fine-tuning of choline metabolism is important for pneumococcal colonization. Mol. Microbiol. 2016, 100, 972-988. [CrossRef]

23. Weyder, M.; Prudhomme, M.; Bergé, M.; Polard, P.; Fichant, G. Dynamic Modeling of Streptococcus pneumoniae Competence Provides Regulatory Mechanistic Insights into Its Tight Temporal Regulation. Front. Microbiol. 2018, 9, 1637. [CrossRef]

24. Chen, J.-D.; Morrison, D.A. Modulation of Competence for Genetic Transformation in Streptococcus pneumoniae. Microbiology 1987, 133, 1959-1967. [CrossRef]

25. Cox, M.M. Regulation of Bacterial RecA Protein Function. Crit. Rev. Biochem. Mol. Biol. 2007, 42, 41-63. [CrossRef] [PubMed]

26. Kowalczykowski, S.C. An Overview of the Molecular Mechanisms of Recombinational DNA Repair. Cold Spring Harb. Perspect. Biol. 2015, 7, a016410. [CrossRef] [PubMed]

27. Michel, B.; Leach, D. Homologous Recombination-Enzymes and Pathways. EcoSal Plus 2012, 5. [CrossRef] [PubMed]

28. Brown, N.C. 6-(p-Hydroxyphenylazo)-uracil: A Selective Inhibitor of Host DNA Replication in Phage-Infected Bacillus subtilis. Proc. Natl. Acad. Sci. USA 1970, 67, 1454-1461. [CrossRef] 
29. Johnston, C.; Caymaris, S.; Zomer, A.; Bootsma, H.J.; Prudhomme, M.; Granadel, C.; Hermans, P.W.M.; Polard, P.; Martin, B.; Claverys, J.-P. Natural Genetic Transformation Generates a Population of Merodiploids in Streptococcus pneumoniae. PLoS Genet. 2013, 9, e1003819. [CrossRef]

30. Ogura, Y.; Imai, Y.; Ogasawara, N.; Moriya, S. Autoregulation of the dnaA-dnaN Operon and Effects of DnaA Protein Levels on Replication Initiation in Bacillus subtilis. J. Bacteriol. 2001, 183, 3833-3841. [CrossRef] [PubMed]

31. Noirot-Gros, M.-F.; Velten, M.; Yoshimura, M.; McGovern, S.; Morimoto, T.; Ehrlich, S.D.; Ogasawara, N.; Polard, P.; Noirot, P. Functional dissection of YabA, a negative regulator of DNA replication initiation inBacillus subtilis. Proc. Natl. Acad. Sci. USA 2006, 103, 2368-2373. [CrossRef]

32. Merrikh, H.; Grossman, A.D. Control of the replication initiator DnaA by an anti-cooperativity factor. Mol. Microbiol. 2011, 82, 434-446. [CrossRef]

33. Soufo, C.D.; Soufo, H.J.D.; Noirot-Gros, M.-F.; Steindorf, A.; Noirot, P.; Graumann, P.L. Cell-Cycle-Dependent Spatial Sequestration of the DnaA Replication Initiator Protein in Bacillus subtilis. Dev. Cell 2008, 15, 935-941. [CrossRef]

34. Goranov, A.I.; Breier, A.M.; Merrikh, H.; Grossman, A.D. YabA ofBacillus subtiliscontrols DnaA-mediated replication initiation but not the transcriptional response to replication stress. Mol. Microbiol. 2009, 74, 454-466. [CrossRef]

35. Velten, M.; McGovern, S.; Marsin, S.; Ehrlich, S.D.; Noirot, P.; Polard, P. A Two-Protein Strategy for the Functional Loading of a Cellular Replicative DNA Helicase. Mol. Cell 2003, 11, 1009-1020. [CrossRef]

36. Seco, E.M.; Ayora, S. Bacillus subtilis DNA polymerases, PolC and DnaE, are required for both leading and lagging strand synthesis in SPP1 origin-dependent DNA replication. Nucleic Acids Res. 2017, 45, 8302-8313. [CrossRef]

37. Rannou, O.; Le Chatelier, E.; Larson, M.A.; Nouri, H.; Dalmais, B.; Laughton, C.; Jannière, L.; Soultanas, P. Functional interplay of DnaE polymerase, DnaG primase and DnaC helicase within a ternary complex, and primase to polymerase hand-off during lagging strand DNA replication in Bacillus subtilis. Nucleic Acids Res. 2013, 41, 5303-5320. [CrossRef]

38. Sanders, G.M.; Dallmann, H.G.; McHenry, C.S. Reconstitution of the B. subtilis Replisome with 13 Proteins Including Two Distinct Replicases. Mol. Cell 2010, 37, 273-281. [CrossRef] [PubMed]

39. Marsin, S.; Lopes, A.; Mathieu, A.; Dizet, E.; Orillard, E.; Guérois, R.; Radicella, J.P. Genetic dissection of Helicobacter pylori AddAB role in homologous recombination. FEMS Microbiol. Lett. 2010, 311, 44-50. [CrossRef]

40. Michel, B.; Sinha, A.K.; Leach, D.R.F. Replication Fork Breakage and Restart in Escherichia coli. Microbiol. Mol. Biol. Rev. 2018, 82, 00013. [CrossRef]

41. Bergé, M.; Mercy, C.; Mortier-Barrière, I.; VanNieuwenhze, M.S.; Brun, Y.; Grangeasse, C.; Polard, P.; Campo, N. A programmed cell division delay preserves genome integrity during natural genetic transformation in Streptococcus pneumoniae. Nat. Commun. 2017, 8, 1621. [CrossRef] [PubMed]

42. Engelmoer, D.J.P.; Rozen, D.E. Competence Increases Survival during Stress in Streptococcus pneumoniae. Evolution 2011, 65, 3475-3485. [CrossRef] [PubMed] 